\title{
Survey of mathematics teachers' static and transformational performance and perspectives for teaching similarity
}

\author{
Robert F. Cunningham and Anthony Rappa \\ Department of Mathematics \& Statistics, The College of New Jersey, Ewing, New Jersey, U.S.A. \\ For correspondence: bobc@tcnj.edu
}

\begin{abstract}
Surveys were used to examine mathematics teachers (15) on their ability to solve similarity problems and on their likely implementation of lesson objectives for teaching similarity. All correctly solved a similarity problem requiring a traditional static perspective, but 7 out of 15 failed to correctly solve a problem that required a more transformational perspective. A set of 10 lesson objectives on similarity were composed using Geometry textbooks, using the Common Core State Standards (CCSS), (NGA Center and CCSSO 2011), and using some generated by the authors. When asked to select from the list of objectives the ones they would most likely implement, teachers favored traditional textbook objectives that might be presented using a static perspective, rather than similarity transformations, manipulatives, or technology that might support a more transformational perspective. In fact, these were among the objectives most likely not included in their lesson plans.
\end{abstract}

Keywords: content knowledge, similarity, transformations

\section{Introduction}

Euclidean geometry normally places congruence before similarity so there may be a tendency to think of similarity as a less important extension of congruence (Usiskin, Peressini, Marchisotto, \& Stanley, 2003), but being able to apply concepts of similarity is a critical aspect of middle and high school mathematics.There have been suggestions that similarity needs to be presented even earlier in the curriculum. For example, Hassan (2015) argues that similarity should be learned before slope, so that one can derive the slope formula from similar triangles, and therefore demonstrate a higher level of mathematical thinking to a concept that is usually taught procedurally. Despite its importance, it has long been known and documented that students struggle with similarity concepts (Cox et al., 2007; Kaput \& West, 1994), especially transformations (Chazan, D., 1988;Seago, et al.,2013).

Seago, et al. (2013)proposes that similarity can be conceptualized with a static perspective or a transformational perspective, and hypothesizes that students who rely on a strictly static perspective perform poorly on similarity tasks. Furthermore, those who possess a transformational perspective can better navigate similarity tasks such as setting up a proportion, including determining which sides and angles are corresponding and what is being scaled.

Implementation of a transformational approach to teaching congruence and similarity is recommended by both the Principles and Standards for School Mathematics (NCTM, 2000) and the Common Core State Standards (CCSS),(NGA Center and CCSSO 2011).However, Seago, et al. (2013) argue that engaging teachers in a transformational approach to similarity is an urgent but largely 
unmet need. This need evidenced itself with some of the middle school teachers in their project who seemed unprepared to implement such anapproach. Even with the recommendations from standards documents, more light needs to be shed on the degree to which teachers are positioned to make instructional decisions that benefit student understanding of similarity.

Both the importance of similarity concepts and student difficulties with them havebeen confirmed, and it is conjectured that including a transformational perspective holds promise for students to develop a deeper understanding of similarity.Because teachers play such an important role in curriculum selection and implementation,their understanding of similarity and their lesson objectives when teaching similarity need careful consideration. Gilbert and Coomes(2010) discuss a need for mathematics teachers to demonstrate a higher and more abstract content knowledge in mathematics. This entails being able to understand and interpret a wide variety of ways to solve a problem or explain a topic.The way that teachers present similarity concepts must embrace this need and both static and transformational perspectives need to be understood. The first purpose of this paper is to compare the performance of inservice mathematics teachers on a similarity problem that emphasize a static approach and on a problem that emphasizes a transformational approach. The second purpose is to compare the types of objectives inservice teachers would likely include in their lesson plans when teaching similarity.

\section{Background}

As early as the mid 1960's some individuals and groups advocated changes to Euclidean Geometry including:coordinate approaches, vector approaches, topics with emphasis on logical structure, NonEuclidean Geometries and Transformation Geometry (Olson, 1969). In particular, Olson conducted one of the first exploratory studies on using transformations in high school geometry.By 1968, there were still no Geometry text available in the United States in which transformations played a fundamental role (Usiskin,1972). Over time support for a transformational approach grew with the publication by the National Council of Teachers of Mathematics (NCTM) of the Curriculum and Evaluation Standards (NCTM, 1989) and the Principles and Standards for School Mathematics (NCTM, 2000)which states that instructional programs prekindergarten through 12th grade should enable all students to apply transformations to analyze mathematical situations.

More recently the Common Core State Standards (NGA Center and CCSSO 2011) defined what students should understand and be able to do in their study of mathematics. This set of standards advocates strongly for a transformational approach to the study of congruence, similarity, and symmetry. More specifically, it advocates for understanding similarity using physical models or manipulatives, transparencies, or geometry softwareand to verify experimentally properties of rotations, reflections, and translations. Further, the CCSS contains 8 standards that refer to transformations. Below is one of the standards that endorses a transformational perspective.

\section{CCSS.Math.Content.HSG.SRT.A.2 \\ Given two figures, use the definition of similarity in terms of similarity transformationsto decide if they are similar; explain using similarity transformations the meaning of similarity for triangles as the equality of all corresponding pairs ofangles and the proportionality of all corresponding pairsof sides (NGA Center and CCSSO 2011).}

Seago, et al. (2013) considers the traditional definition of similar figures as those that have corresponding sides that are in proportion and corresponding angles are congruent. They associate this with the static perspective, which emphasizes the mechanical application of proportion. This perspective is conceptualized in discrete terms as a numeric relationship between two figures. 
This is in contrast to the non-traditional dynamic definition of similar figures that one figure is similar to another if the second can be obtained from the first by a sequence of rotations, reflections, translations, and dilations. This definition is associated with the more transformational perspective, which requires the ability to move a figure to find the correct correspondence. This perspective focuses on enlarging or reducing figures proportionally to create a class of similar figures. This perspective would be associated with the use of manipulatives, transparencies, or geometry software to illustrate the dynamic quality of transformations. Since both the static and the transformational perspectives can enhance student understanding and ability to analyze mathematical situations(Seago, et al. 2013), they need to be part of a teacher'scontent knowledge about similarity.

Shulman (1986) suggests that there are three categories of teacher content knowledge: subject matter content knowledge, pedagogic content knowledge, and curricular knowledge. The two perspectives on teaching similarity will be looked at through the lens of subject matter content knowledge and pedagogic content knowledge in this study. Shulman describes the category of pedagogic content knowledge as

... for the most regularly taught topics in one's subject area, the most useful forms ofrepresentationof those ideas, the most powerful analogies, illustrations, examples, explanations, and demonstrations - in a word, the most useful ways of representing and formulating the subject that make it comprehensible toothers.

Mathematics teachers must have the subject matter content knowledge necessary to solve similarity problems. In addition, they need to have the pedagogic content knowledge necessary for selecting the most useful ways to represent and formulate similarity that makes it comprehensible to their students. Both the static and transformational perspectives of similarity need to be part of the lessons showcased to students. Consequentially, teachers need to develop lesson plans with objectives aligned with both perspectives.

In this study we addresses the following questions:

1) Given a sample of inservice mathematics teachers, how will their performance on a similarity problem requiring a static approach compare to that of a problem requiring a transformational approach?

2) Given a sample of inservice mathematics teachers, what types of objectives would teachers include in their lesson plans when teaching similarity?

\section{Method}

Participants

Current mathematics teachers (15) from different public schools in New Jersey were surveyed. Each had graduated with degrees in secondary mathematics education from the same highly selective 4year undergraduate institution in New Jersey. The institution has a solid reputation of preparing excellent mathematics teachers. All of the teachers had experience teaching Geometry. The years of experience varied from 2 year to 23 years.

\section{Instruments}

Surveys were piloted with 25 preservice teachers and two experienced mathematics educators. The surveys were then revised to better answer the research questions. The participants in the study were asked to voluntarily complete aneight-question Qualtricsurvey involving geometric similarity. The survey included seven content questions and one question involving lesson objectives.Serving as 
sources for the content questions and objectives were three Geometry textbookscommonly used in local schools: Contemporary Mathematics in Context: A Unified Approach (Coxford, et al., 2003), Mathematics Applications and Concepts (Bailey, et al., 2006), and Pacemaker Geometry (Bauer, et al., 2003).

The last question in the survey listed 10 lesson objectives. Four objectives come from the Geometry textbooks, three were based on recommendations made in the Common Core State Standards and three were author generated. The survey required participants to list which objectives they would most likely include, would possible include, and which they wouldnot likely includein their lessons on similarity.Each of these three categories could contain from 0 to 10 objectives.

\section{Procedure}

Surveys were distributed using the e-mail addresses of 45 former secondary mathematics education majors. This number was reduced because some of the individuals responded that they were no longer teaching mathematics. Also contributing to the reduction were e-mails addresses that were inactive and some individuals simply did not respond to the voluntary survey. Participants were required to give an answer to each content question and to explain the work behind the answer. There was no specified time limit on the survey, and the participants were allowed to use any resources at their disposal.

\section{Results}

The Qualtric surveys were analyzed and the similarity problem from the survey that represented a static perspective appears below in Figure 1. All 15 teachers showed both correct work and answer for this problem.

The two figures are similar. If possible, find the value of "x." Show all work.
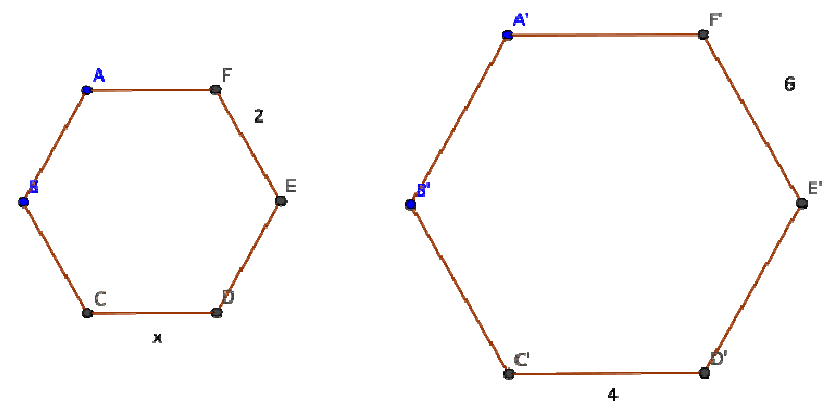

Figure 1. Similarity Problem Representative of a Static Perspective.

The similarity problem from the survey that represented a transformational perspective appears below in Figure 2. Of the 15 teachers surveyed, 8 indicated that it was impossible since there were two possible correspondences and they gave both possible answers. Of the other teachers, 5 gave a single answer that considered only one possible correspondence, and 2 gave a single answer that also contained an errorin setting up a proportion. 
The triangles are similar. If possible, find the area of the one on the left.Explain your reasoning.

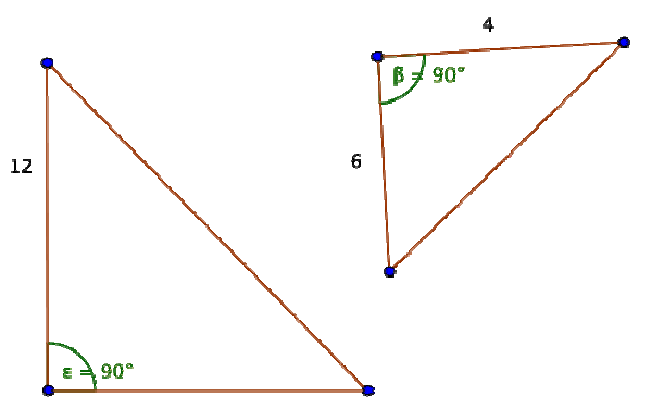

Figure 2. Similarity Problem Representative of a Transformational Perspective

The last problem on the survey listed 10 lesson objectives and they are shown in Table 1 below. Four of the objectives were taken from Geometry textbooks (T1, T2, T4, and T6), three objective were taken from the Common Core State Standards (CCSS 7, CCSS 9, and CCSS10) and three objectives were generated by the authors (A3, A5, and A8).

Table 1.Sample Lesson Objectives on Similarity

T1.

T2.

A3.

T4.

A5.

T6.

CCSS 7.

A8.

CCSS 9.

CCSS 10.
To find missing measures of similar polygons. (Bailey, et al., 2006).

To apply similar polygons to real-world situations given in word problems.

(Bailey, et al., 2006).

To use writing to illuminate similarity. (author generated).

To use similarity statements like AA, SAS, and SSS and to determine if polygons are similar. (Bailey, et al., 2006).

To relate similarity to previous knowledge of algebra (e.g. slope). (author generated).

To use the relationship among lengths, area and angles of similar polygons.

(Bauer, et al., 2003).

To use manipulatives to illustrate similarity.

To relate similarity to previous knowledge of topics like ratio and proportions.

(author generated).

To use technology to introduce similarity. (Ex. Geo Sketchpad, Geogebra,etc.).

To use similarity transformations to explain the meaning of similar polygons.

(CCSS.Math.Content.HSG.SRT.A.2)

The teachers were more likely to include the textbook objectives rather than those representing the CCSS. Figure 3.below shows the frequency that each objective was placed in the category of most likely include, possibly include, and not likely include in lesson plans on similarity. 


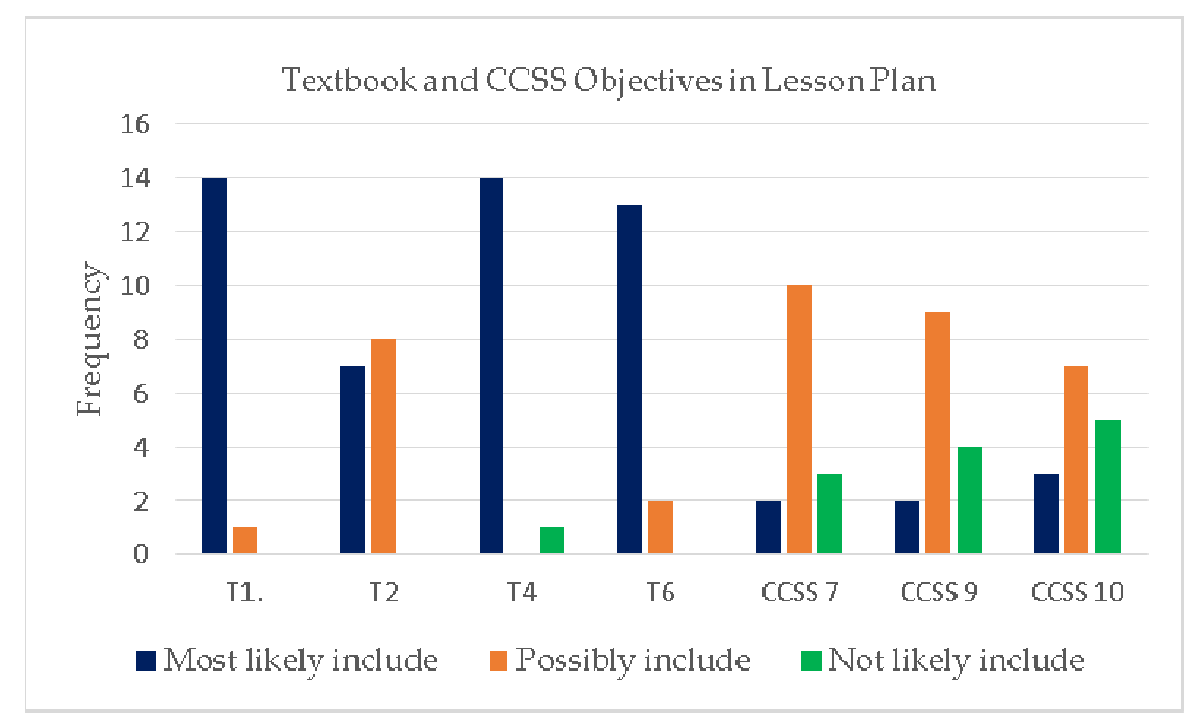

Figure 3. Results from Mathematics Teachers' Surveys ( $\mathrm{n}=15)$.

\section{Conclusion}

While the entire sample of mathematics teachers was able to correctly solve a similarity problem that required a static perspective, the same cannot be said for a similarity problem that required a more transformational perspective. This problem asked if it was possible to find the area of the left triangle, given that the two triangles were similar. While this transformational problem required an addition step of finding area, this was not the source of teacher difficulty. The correct answer was that it was not possible to find the area, because there were two possible correspondences.

By rotating the triangle on the right, anappropriate proportion to find the needed side is $4 / 12=6 / x$ then $x=18$.This results in the area being 108 square units. However, a correspondence found by reflecting the triangle on the right yields an appropriate proportion $6 / 12=4 / x$ then $x=8$. This results in the area being 48 square units. The teachers (8) who correctly solved the problem were able to consider the possibility of two different correspondences using different transformations. They demonstrated the ability to navigate the similarity task which points to their conceptualization of a transformational perspective as suggested by Seago, et al. (2013).

The teachers that were incorrect (7) considered only one possible correspondence and may have confined their conceptualization to a static perspective.Their subject content knowledge was limited as they focused on procedures without connection to meaning, understanding or application (Leinwand, et al., 2014). For theseteachers, similarity may have been viewed more procedurally as a numerical relationship in which you set up the singular proportion and the numerical answer is found. As reported by Seago, et al. (2013) relying on a strictly static perspective can impede performance on similarity tasks.

Not only did some of the teachers in this sample display a misstep in subject matter content knowledge, but also in pedagogic content knowledge necessary for selecting the most useful ways to present similarity that might make it comprehensible for their students. They gravitated toward including textbook objectives with a static perspective rather than objectives that promoted a transformational perspective. For example, 14 out of 15 teachers would most likely include the objective: To use similarity statements like AA, SAS, and SSS and to determine if polygons are similar. (Bailey, et al., 2006), but only 3out of 15 would most likely include the objective:To use similarity transformations to explain the meaning of similar polygons (CCSS.Math.Content.HSG.SRT.A.2).In 
addition, the three objectives that were categorized most often as not likely to be included were those that could be used to demonstrate the dynamic quality of transformations involving: manipulatives, technology, or similarity transformations themselves.

In summary, only a small sample of mathematics teachers were surveyed and even the survey itself was limited in scope, but there appears to be more of a focus on the static perspective rather than the transformational perspective held by these teachers.Some of this focus maybe attributable to familiarity with the textbook objectives selected.Nevertheless, with the continuing alignment of textbooks with the CCSS, they will have to accommodate objectives that focus on similarity transformations. Since teachers play such an important role in in curriculum selection and implementation, they must develop a higher level of pedagogic content knowledge so that they can understand and interpret a variety of ways to solve problems and explain a topic (Gilbert \&Coomes, 2010). Standards documents recommend using similarity transformations and the textbook objectives that focus on a static perspective remain important.But, teachers must select and implement lesson plans with objectives that align with both the static and transformational perspectives so that students can develop a deeper understanding of similarity.

\section{References}

Bailey, R., Day, R.,Frey, P., Moore-Harris, B., Ott, J. M., Pelfrey, R., Howard, A.C., Hutchens, D.T., McClain, K., Price, J., Vielhaber, K., \& Willard, T, (2006). Similar Polygons. In MathematicsApplications andConcepts (Teacher Wraparound ed., Vol. 3, pp. 178-183). Columbus, OH:Glencoe/McGraw-Hill.

Bauer, E., Brorein, S., Jacobus, J., \&Visco, J. (2003). Pacemaker Geometry (Teacher's Answer ed.) (J. Brooks, D. Camaleri, P. Dunsay, A. Feldman, E. Fernald, M. E. Gilbert, J. Kelly, \& D. R. Pollak, Eds.). Parsippany, NJ: Globe Fearon Inc.

Chazan, D. (1988). Similarity: Exploring the Understanding of a Geometric Concept (Technical Report No. 88-15). Washington, DC: Office of Educational Research and Improvement(ED).

Cox, D. C., Lo, J. J., \& Mingus, T. (2007). Low achieving middle school students' conceptions of same shape. In T. Lamberg\& L. R. Wiest (Eds.),Concepts and Theorems About Similarity School Science and Mathematics 413 Proceedings of the 29th AnnualMeeting of the North American Chapter of the International Group for the Psychology of Mathematics Education (pp. 130-132). Stateline, NV: University of Nevada, Reno.

Coxford, A.F., Fey, J.T., Hirsch, C.R., Schoen, H.L., Burrill, G., Hart, E.W., Watkins, A.E.,M.J., Ritsema, B.E., \& Walker, R.K. (2003). Flexible Quadrilaterals. In Contemporary Mathematics in Context: A Unified Approach (Teacher's Guide ed. pp. 368383). Columbus, OH: Glencoe/McGraw-Hill.

Gilbert, M. J., \&Coomes, J. (2010). What Mathematics Do High School Teachers Need toKnow? The Mathematics Teacher, 103(6), 418-423.

Hassan, S. (2015). So you're saying we should teach congruence and similarity before teaching slope? [Blog post]. Retrieved from Eureka Math website:

$<$ https://medium.com/eureka math/so-you-re-saying-we-should-teach-congruence-

and-similarity-before-teaching-slope ad7004480c57\#.bwshcn k04>, (accessed May,2016).

Kaput, J. J., \& West, M. (1994). Missing value proportional reasoning problems: Factors affecting informal reasoning patterns. In G. Harel\& J. Confrey (Eds.), The development of multiplicative reasoning in thelearning of mathematics (pp. 237-292). Albany, NY: State University of New York Press.

Leinwand, S., Brahier, D. J., Huinker, D., Berry III, R.Q., Dillon, F.L., Larson, M.R., Leiva, M.A., Martin, W.G., \& Smith, M.S. (2014). Progress and Challenge. In Principles to Actions:Ensuring Mathematical Success For All (pp. 2-3). Reston, VA: The National Council of Teachers of Mathematics.

National Council of Teachers of Mathematics, (1989). Curriculum and Evaluation Standards.Reston, VA:Author.

National Council of Teachers of Mathematics, (2000). Principles and Standards for SchoolMathematics. Reston, VA: Author.

National Governors Association (NGA) Center for Best Practices \& Council of Chief State School Officers (CCSSO). (2011). Common core state standards in mathematics.Retrieved from http://www.corestandards.org/assets/CCSSI_Math\%20Standards.pdf, (accessed June, 2015).

Olson, A. T. (1969, October). High School Plane Geometry through Transformations: An Exploratory Study (Research Report No. 760541-70-1007-06). Washington, D.C.: Office of Education (DHEW).

Seago, N., Jacobs, J., Driscoll, M., Nikula, J., Matassa, M., \& Callahan, P. (2013). Developing Teachers' Knowledge of a Transformations-Based Approach to Geometric Similarity. Mathematics Teacher Educator, 2(1), 74-85.

Shulman, L. S. (1986). Those Who Understand: Knowledge Growth in Teaching. Educational Researcher, 15(2), 4-14.

Usiskin,Z.P.(1972). The effects of teaching Eudideangeometry via transformations on student achievement and attitudesin tenth-grade geometry. Journal for Research in MathematicsEducation3( $(9249-239$.

Usiskin, Z., Peressini, A., Marchisotto, E.A., \&Stanley, D. (2003).Mathematics for high school teachers: an advanced perspective. Prentice Hall. Upper Saddle River, New Jersey. 